\title{
EDUCAÇÃO FÍSICA, LINGUAGEM E EDUCAÇÃO INFANTIL: UMA APROXIMAÇÃO COM PAULO FREIRE
}

\author{
UIRÁ dE SIQUEIRA FARIAS \\ Universidade São Judas Tadeu (USJT), São Paulo, Brasil \\ Daniel Teixeira Maldonado \\ Instituto Federal de São Paulo (IFSP), São Paulo, Brasil \\ GRACIELE MASSOLI RODRIGUES \\ Universidade São Judas Tadeu (USJT), São Paulo, Brasil
}

Resumo: Esse ensaio foi produzido na perspectiva de defender a ideia de que as aulas de Educação Física "com" a Educação Infantil podem possibilitar que as crianças leiam criticamente o mundo a partir da problematização de uma ecologia de saberes, construídos historicamente, sobre as práticas corporais e o corpo. Além disso, problematizamos a relação entre movimento e gesto, defendendo que a gestualidade humana é dotada de significados, sendo compreendida e ressignificada de acordo com a cultura dos praticantes das danças, ginásticas, esportes, lutas, jogos e brincadeiras. Por fim, mostramos que esse avanço epistemológico da área se deu, dentre muitas particularidades, pela fundamentação teórica freireana de leitura do mundo, principalmente, devido a esse componente curricular estar inserido na área de Linguagens na Educação Básica.

Palavras-chave: Educação Física. Educação Infantil. Linguagens. Leitura de Mundo.

\section{PRIMEIRAS REFLEXÕES}

\begin{abstract}
Afinal, o espaço pedagógico é um texto para ser constantemente "lido", "interpretado", "escrito" e "reescrito". Neste sentido, quanto mais solidariedade exista entre o educador e educandos no "trato" deste espaço, tanto mais possibilidades de aprendizagem democrática se abrem na escola (PAULO FREIRE, 2011, p. 85).
\end{abstract}

A Educação Física (EF) se estabeleceu na área de linguagens e isso tem promovido um excelente ambiente para explorar diversas discussões dos temas da cultura corporal nas várias etapas da Educação Básica. Mais recentemente, a Educação Infantil (EI), em alguns lugares do país, passou a contar com as aulas de EF. Com essa inserção, mesmo que ainda seja de forma facultativa, pois as leis não estabelecem que essas aulas devam ser efetivadas por professor/a do componente curricular, estamos 
notando que práticas político-pedagógicas vêm acontecendo nesse ciclo de escolarização, entrelaçando temas da cultura corporal e as linguagens.

Recentemente, estudos que relacionam a função social da EF com as ideias freireanas têm trazido reflexões extremamente potentes que estão movendo, reposicionando e recriando essa literatura para os debates (BOSSLE et al., 2020). Na El, áreas como a sociologia da infância, pedagogia da infância, antropologia e história têm conduzido importantes modificações na visão que temos da infância e das crianças, inclusive assumindo que não temos mais "a infância", e sim "as infâncias", que são vividas pelas crianças nos mais diferentes contextos pelo mundo. Grupo esse que é mais um entre tantos marginalizados pelo mundo ocidental por não ter a chance de se envolver em nenhum processo de decisão social (SARMENTO; TOMÁS, 2020).

[...] o conceito de infância, apresentando-o como categoria social do tipo geracional, universal e permanente, ainda que marcada pela desigualdade social e pela diversidade, através da interceção com outras categorias sociais, designadamente classe, género, etnia, escolaridade, espaço geográfico, credo religioso, orientação sexual. Pensar a infância numa perspectiva sociológica crítica implica a desconstrução da conceção normativa da infância e a focalização dos fatores sociais que, em simultâneo, contribuem para a justificação da universalidade dos direitos da criança e para a desigualdade da sua aplicação (SARMENTO; TOMÁS, 2020, p.17).

A partir dessa conjuntura, neste ensaio vamos aproximar ideias que têm provocado diversas reflexões sobre a leitura de mundo e as práticas corporais. Neira (2014) menciona que, mediante contribuições da sociologia, antropologia, história, filosofia, política, semiótica e, mais recentemente, dos estudos culturais, a antiga preocupação com a aprendizagem dos movimentos nas aulas de EF foi substituída pela tematização da cultura corporal, que pode ser compreendida como uma parcela da cultura mais ampla que abarca todos os conhecimentos e representações relativos às práticas corporais.

Por sua vez, as práticas corporais são os produtos da gestualidade sistematizada com características lúdicas, materializando-se nas brincadeiras, danças, lutas, esportes e ginásticas. Assim, podemos considerar que fazem parte da cultura corporal desde as regras da amarelinha até o desenho tático do futebol, passando pelos gestos do balé, a história do judô e os nomes dos aparelhos de ginástica, dentre outros saberes que envolvem essas manifestações culturais (NEIRA, 2014).

Ao focalizarmos a El, é interessante entender que as crianças são sujeitos que produzem culturas e constroem conhecimentos, mesmo antes de ler as palavras. As crianças leem o mundo a sua maneira, não sabem menos que os adultos, elas sabem coisas diferentes que, muitas vezes, são desvalorizadas e desprezadas pelo adultocentrismo que tenta embutir nas crianças um projeto de adulto em miniatura (FREIRE, 2011; 2013; 2015; 2017; GOELZER; HENZ, 2020).

Nas aulas de EF, crianças da El, a partir de suas leituras de mundo, podem ser convidadas a ler as práticas corporais, não mais como um movimento mecânico, ou os 
FARIAS, U. de S.; MALDONADO, D. T.; RODRIGUES, G. M.

tão conhecidos circuitos, mas sim, como gestualidade carregada de sentidos, significados e cultura. Além disso, elas vão percebendo que ali, na leitura que fazem dos gestos, vão descobrindo que existe uma ecologia de saberes acontecendo a todo momento.

\section{LER O MUNDO NAS AULAS DE EDUCAÇÃO FÍSICA COM A EDUCAÇÃO INFANTIL}

Documentos como o Referencial Curricular Nacional da Educação Infantil (RCNEI) (BRASIL, 1998), as Diretrizes Curriculares Nacionais para a Educação Infantil (DCNEI) (BRASIL, 2010) e a Base Nacional Comum Curricular (BNCC) (BRASIL, 2017), a partir da análise feita por Mello et al. (2016), demonstram importantes avanços para a organização de políticas educacionais para essa etapa da Educação Básica, saindo de um olhar puramente psicologizante, com as RCNEl's, e alcançando outros debates, como aqueles travados na sociologia da infância. A organização curricular nas DCNEl's passa a ter as linguagens como foco, assim como o corpo/movimento ganham outro sentido, ou seja, são considerados formas de expressão, tendo o jogo e a brincadeira como objeto central das aprendizagens. Já na BNCC, a concepção de criança segue a mesma lógica, pautada na sociologia da infância, e a organização curricular ganha a contribuição dos campos de experiências inspirados na perspectiva malaguzziana das cem linguagens (EDWARDS; GANDINI; FORMAN, 2018), na qual o corpo/movimento passa por uma importante transformação, ganhando outros contornos, trazendo sentidos e significados por meio de várias linguagens. Além disso, as brincadeiras são consideradas um direito das crianças.

Reconhecemos a importância desse aparato curricular para a função social da El neste momento histórico. Todavia, por mais que esse ciclo de escolarização não se organize por disciplinas, a EF já é uma realidade nesse contexto. Diante disso, entendemos que os projetos educativos que envolvam os saberes da cultura corporal devem seguir uma lógica sempre multidisciplinar em que todas as áreas de conhecimento reconheçam as crianças como centrais, autoras e atrizes, detentoras e produtoras de saberes, e que as interações e as brincadeiras, assim como as diversas práticas corporais enriqueçam a El de outros conhecimentos, que "COM" as crianças poderão ampliar a leitura de mundo, independentemente se com o/a professor/a de EF ou com as pedagogas.

Assim, ressaltamos que "ler o mundo" pode recair simplesmente na ideia de codificar palavras, mas devemos compreender que vai muito além disso. A leitura de mundo é precedida do ato de decodificar as letras, pois a realidade e a linguagem vivem uma relação de dinamicidade entre texto e contexto (FREIRE, 2017). A genialidade da ideia de Paulo Freire com relação à alfabetização estava exatamente em proporcionar uma leitura politizada das palavras geradoras, inclusive usando imagens, trazendo todo o contexto e realidade que aquela palavra podia significar para as pessoas no seu círculo de cultura (FREIRE, 2013; 2015).

Assim, diante dessa breve relação com Paulo Freire, fazemos a defesa da EF inserida na área de linguagens. Nessa conotação, o ato político-pedagógico do/da professor/a desse componente curricular pode instigar as crianças, jovens e adultos a lerem as práticas corporais, interpretá-las, escrevê-las e reescrevê-las, dando novos sentidos, significados e transformando-as (FREIRE, 2011). 


\begin{abstract}
Isso reforça a ideia de que a linguagem não se restringe à oralidade, mas é possível entender como linguagem as diversas formas de comunicação e expressão, tais como a pintura, o poema, a escultura, bem como todos os elementos da cultura corporal (EHRENBERG, 2014, p. 186).
\end{abstract}

Na discussão de uma brincadeira, o brincar é mais um saber dentre os vários que a envolvem e que podem ser vividos. Outros conhecimentos dessa mesma prática corporal podem ser tratados por meio de poesia, música, sua história, aspectos políticos, implicações biológicas e fisiológicas, relações com as questões de gênero e étnicoraciais. A nossa visão de mundo nos conduz a interpretar um mesmo conhecimento por diferentes linguagens, a partir de uma ecologia de saberes (SOUSA SANTOS, 2011).

Acreditamos que essa leitura e interpretação do mundo deva ser mediada pelo/pela professor/a para que as crianças possam compreender criticamente, por exemplo, uma brincadeira, trazendo-as para o centro da discussão, dando voz a elas e, mais do que isso, ouvindo-as, permitindo que digam suas palavras e construam seus argumentos (SILVA; MAFRA, 2020). Dessa forma, é possível romper com as práticas que fazem as crianças memorizarem, estimulando a sua curiosidade epistemológica, recorrendo a uma pedagogia da pergunta, em detrimento de uma pedagogia em que o docente só narra/disserta seus ditos conhecimentos. É arriscar-se, aventura-se, permitir o próprio parto da rebeldia. Não é, e nunca será uma tarefa fácil, propor uma prática político-pedagógica nessa direção. Mas se queremos contribuir para a formação de pessoas que leiam o mundo criticamente, é preciso construir "COM" elas, desde cedo, os arranjos pedagógicos que potencializem a participação no e "COM" o mundo, ou seja, "COM" diálogo, "COM" amorosidade e "COM" horizontalidade das relações (FREIRE, 2011; 2013; 2015; 2017).

A discussão sobre a EF na área de linguagens é algo que nos encanta e, ao mesmo tempo, ainda nos traz dúvidas. Caberia como sugestão a preposição "COM", pois a EF necessita estar "COM" a área de Linguagens, "COM" as diferentes linguagens. $\mathrm{O}$ componente curricular, ao longo de sua história, passou por diversas transformações (COSTA; ALMEIDA, 2018). Destacamos a integração da EF na área de Linguagens, possibilitando que o corpo e as práticas corporais possam ser lidas em diversificadas lentes, levando em consideração a nossa ação didática "COM" as crianças da El, sendo este, um ponto de grande atenção.

\footnotetext{
Reelaboramos, em relação a ele, o nosso olhar. Nele podemos ver agora não somente músculos, ossos, capacidade cardíaca e o quanto de performático poderia haver na execução de determinado movimento.

"Desnaturalizamos" o corpo de sua condição biológica e nos sensibilizamos com a gama de elementos culturais que também fazem parte do movimento humano (COSTA; ALMEIDA, 2018, p. 2).
}

Após contribuições de outras áreas como a sociologia, antropologia e filosofia, o corpo passa a ser foco de estudos e a cultura ganha destaque, saindo de um viés somente biológico e passando a ser compreendido por um olhar sócio-histórico. A partir 
FARIAS, U. de S.i MALDONADO, D. T.; RODRIGUES, G. M.

dessa virada culturalista, intensos debates acontecem e o corpo passa a ser associado a uma interpretação sempre discursiva (COSTA; ALMEIDA, 2018).

A linguagem corporal é um dos aspectos da cultura e, para problematizar suas temáticas, é preciso compreender e fazer uma leitura crítica da própria prática e da realidade (EHRENBERG, 2014, p. 187).

Neira e Nunes (2021) evidenciam que as discussões da EF na área de Linguagem aparecem demarcadas em quatro documentos: em meados de 1970, em guias curriculares juntamente a outras áreas em uma matéria denominada "comunicação e expressão". Depois disso, a EF é inserida na área de Códigos e Linguagens, nos Parâmetros Curriculares Nacionais, na década de 1990. Em 2013, na Diretrizes Curriculares Nacionais da Educação Básica e em 2017 da Base Nacional Comum Curricular, essa lógica se confirma e o componente se estabelece nesse contexto.

Corroborando o estudo de Costa e Almeida (2018), Neira e Nunes (2021) também suscitam que a discussão das linguagens na EF ganha outros contornos com a proximidade das Ciências Humanas. Porém, os avanços epistemológicos ainda são sutis no campo acadêmico, fato que causa dúvidas para aqueles/as que estão atuando nas escolas, pois, como salientam os autores, faltam bases conceituais para explicar os fundamentos da EF na área de Linguagens.

Entretanto, é possível perceber que o debate vem se movimentando com contribuições de diversos autores/as, no entanto, ainda sem grandes efeitos para superar metodologias pautadas na psicomotricidade. A obra de Mattos e Neira de 2000, assim como as ideias de Pierre Parlebas, são aquelas que trazem discussões com maiores elementos, além das obras Coletivo de Autores de 1992 e Mauro Betti de 1994 e 2007. Por último, o currículo cultural, que se apoia no campo da linguagem para trazer uma discussão em que a $\mathrm{EF}$, na área de Linguagens, permite que as práticas corporais sejam lidas pelas pessoas, resultando na interpretação de códigos, gestos e seus significados culturais (NEIRA; NUNES, 2021).

Após adotar a cultura corporal como sendo objeto de ensino, discutindo as manifestações culturais por meio das práticas corporais, como: jogos, brincadeiras, danças, lutas, esportes, ginásticas, entre outras, os/as docentes de EF, ao desenvolverem suas práticas político-pedagógicas, devem trazer elementos que movam os/as educandos/as no sentido de ler e interpretar essas práticas que são produzidas pela/através da linguagem corporal (NEIRA, 2017).

A partir do momento em que os seres humanos atribuem "significados" às práticas corporais, sendo assim considerados gestos, o movimento já não é resultado puro e simplesmente de comandos neurais, mas expressa uma determinada visão de mundo, sentimentos e emoções (NEIRA, 2017). Nas palavras de Neira:

O gesto é um signo. É o menor elemento da gramática produzida pela linguagem corporal. Organizados de forma sistemática os gestos configuram as práticas corporais que, por sua vez, nada mais são do que artefatos culturais (NEIRA, 2017, p. 2).

É partir da assimilação das práticas corporais como textos e da interpretação de 
seus gestos que passamos a ter contato com seus sentidos e significados. São produções culturais que se comunicam umas com as outras, abrindo possibilidades para nossas construções ou transformações culturais. Mesmo em um território de disputa, a cultura vai se estabelecendo pelas relações sociais, porém não podemos ser ingênuos e achar que não existem culturas que, a todo momento, querem estabelecer sua força em detrimento de outras menos favorecidas (NEIRA, 2017).

Ressaltamos que em uma educação que objetiva ser emancipadora, não cabe à EF cair nas armadilhas de favorecer, por meio da linguagem corporal, o status quo de determinadas práticas corporais. É a própria "invasão cultural”, alertada por Paulo Freire (2013), que impõe sua visão de mundo, às vezes camuflada como amigo querendo ajudar, mas, na verdade, é a invasão econômica e cultural operando como "lobo em pele de cordeiro". Pense você, leitor e leitora, nas práticas corporais que mais são tratadas nas aulas do componente, por exemplo, os esportes de quadra podem ser considerados uma invasão cultural?

As relações de poder estão sempre atuando em nossas aulas, como se a cultura do opressor se sobrepusesse à cultura do oprimido, no entanto, não existe cultura melhor ou pior. Como Paulo Freire bem discute, é preciso ser mais, ou seja, nessa busca não se pode ficar isolado, individualizado, pois a comunhão das culturas, dos diversos signos e sentidos, visitados sempre de forma crítica, contribui para a valorização e emancipação dos indivíduos para serem mais (FREIRE, 2013).

Destacamos outro ponto: o termo "práticas corporais" tem sido alvo de diversos debates nos vários campos de conhecimento, como apontam Lazzarotti Filho et al. (2010). Porém, é na EF que esse termo tem sido utilizado com maior frequência. Nesse contexto das Ciências Humanas e Sociais, principalmente na educação, o termo "práticas corporais", surge em oposição à visão somente biológica e seu pragmatismo, trazendo danças, lutas, ginásticas, esportes, jogos e brincadeiras como manifestações culturais expressas na dimensão corporal (LAZZAROTTI FILHO et al., 2010; SILVA; LAZZAROTTI FILHO; ANTUNES, 2014).

Mesmo com todo esse debate sobre a EF na área de linguagem, algumas dúvidas ainda se mantém, principalmente entre nós, que estamos na realidade escolar, como foi possível perceber no estudo de Costa e Almeida (2017). Outros dois grandes autores da área (Mauro Betti e Valter Bracht) trazem tensionamentos ao tratar do tema, cada um com fundamentações distintas, além dos professores Marcos Neira e Mario Nunes. $O$ debate trazido por esses autores enriquece as discussões, mas compete a cada professor/a decidir o caminho a ser percorrido.

Quando pensamos a EF constituindo-se como um tipo de linguagem, nos aproximamos das ideias freireanas de "leitura de mundo" e todas as nuances que estão por trás de seus pensamentos. É necessário deixar demarcado que estamos inclinados a uma posição que foi e vai nos constituir enquanto seres no mundo e "COM" o mundo, sempre na perspectiva do inacabamento, essa provisoriedade temporal que o ser humano carrega. Estamos sempre em elaboração e reelaboração do nosso viver, porém não é possível dizer que ler o mundo significa fazê-lo de forma ingênua, desconectado das opressões vividas, principalmente essa realidade que esmaga os esfarrapados do mundo. É uma leitura que carrega todas as marcas histórico-sociais que constituíram a 
sociedade, principalmente a brasileira, ou seja, histórica, política, econômica, biológica, cultural e social (FREIRE, 2011; 2013; 2015; 2017).

A leitura que as crianças fazem do mundo é dotada de suas visões, bonitezas e estéticas, sem perder de vista que essas infâncias são singularidades enquanto atores e atrizes que são, sendo a infância uma categoria geracional da sociedade (QVORTRUP, 2010; FREIRE, 2013; SARMENTO, 2013). A EF como um componente curricular, se valendo de uma prática político-pedagógica, fundamentada na educação como prática da liberdade (FREIRE, 2011; 2013; 2015), ao tematizar as múltiplas práticas corporais pode "COM" as crianças, ler tais manifestações da cultura corporal e discutir os vários saberes que elas podem revelar, sem perder de vista que a leitura do mundo antecede a leitura da palavra (FREIRE, 2017).

A partir da leitura de mundo das crianças, considerando o ser humano em sua inteireza, um ser sempre em processo de busca, que se faz historicamente, elas vão trazer para as aulas de EF suas experiências vividas, a experiência existencial, como ser humano e não como objeto, não como coisificação (FREIRE, 2015).

Se compreendida assim, é também encharcada de importância histórica, pois ela já faz parte da relação dos seres humanos no mundo, com o mundo e com os outros. Assim, podemos considerar que a infância faz parte do processo de humanização, momento (tanto quanto as outras fases geracionais) de aprender a reconhecer-se e a construir-se permanentemente (PELOSO; PAULA, 2020, p. 190).

Permitir que as crianças digam suas próprias palavras e que sejam ouvidas, é parte de um projeto de educação para a liberdade, em que a curiosidade por ler o mundo é a propulsão que potencializa a criticidade, possibilitando a elas o ser mais. $O$ que está em jogo é a constante luta contra a acomodação ou o ajustamento que a educação bancária instaura. Desde cedo, é necessário que as várias linguagens sejam interpretadas pelo viés crítico (FREIRE, 2015), isso implica discutir com as crianças as práticas corporais pelas suas interpretações, numa interação constante de visões de mundo e de pontos de vista.

É possibilitando essa construção "COM" participação efetiva das crianças que vamos aprendendo de forma horizontal e trazendo essa ideia da participação, em que as crianças leem as práticas corporais. Encontramos em Scarazzatto (2020) um interessante debate sobre o gesto e o movimento que enriquece ainda mais essa discussão. A autora, fundamentada em Bakhtin e Vigotski, defende o gesto "como uma construção coletiva, como possibilidade de significação, interpretação, comunicação que acontece histórica e culturalmente". O movimento, na explicação de Scarazzato, é o resultado puramente mecânico de contrações musculares que rompe com a inércia, desconectado do contexto, uma ação isolada. Na defesa da autora, o gesto ganha centralidade nesse debate, pois permite que as práticas corporais sejam resultado do diálogo "COM" o mundo através dos significados em que os gestos expressão são significações construídas pelas pessoas.

Entender que o movimento não é o resultado apenas físico e biológico significa superar essa visão e refletir sobre como essas práticas corporais carregam sentidos vivos, produzidos por relações socioculturais. Tudo isso chega nesse ponto devido ao 
deslocamento de uma discussão das Ciências Naturais para as Ciências Humanas, em que a lente das Ciências Sociais contribui para compreender o movimento humano de outras formas, resultado de diversas transformações sociais, históricas e culturais. Sendo assim, o movimento conota-se como linguagem, pois é dotado de sentidos, gesto em sua dimensão cultural (SCARAZZATTO, 2020).

É necessário encarar as aulas de EF "COM" a El como momento também de compreender a realidade, onde as crianças e professor/a, entre suas consciências, elaboram e reelaboram conhecimentos, é a pura dialogação dinamizada na sala de aula. O conhecimento é mediado pelo discurso que, em sala, se dinamiza entre elaborações e compreensões. Assim, o gesto, mediado pelo discurso, ganha outros sentidos e se reelabora (SCARAZZATTO, 2020).

As práticas corporais são frutos de uma construção social de grupos distintos, que se organizam socialmente e que simbolizam sentidos e significados. Assim, o gesto é resultado ideológico, ou seja, o signo é ideológico, mas ganha vida nas relações sociais estabelecidas entre os seres humanos (SCARAZZATTO, 2020). Assim como a visão de mundo, a leitura de mundo, só ganha sentido e significado pelas interações sociais estabelecidas entre o sujeito "COM" o mundo e "COM" as pessoas, resultado de uma construção sempre dialética, dialógica e ideológica. Seja texto ou discurso, o gesto ganha vivacidade pela interação "COM" o outro e "COM" o contexto, em que caberá sempre realizarmos sua interpretação.

\footnotetext{
O gesto não é "pura reação de um organismo individual", ele é interação, comunicação, expressão, organização formas de olhar e estar no mundo. Arriscarei dizer aqui que o gesto constitui-se na interação entre corpo e linguagem, no corpo e na linguagem, pelo corpo e pela linguagem, numa relação indissociável, numa relação dialógica em que um elemento complementa o outro (SCARAZZATTO, 2020, p. 150).
}

Dessa forma, a EF, compondo a área de Linguagens, entendida como educação, pode "COM" as crianças, jovens e adultos codificar a realidade, descodificar e recodificála e com essa polissemia de olhares, significar diferentes formas de ler o mundo (FREIRE, 2013).

Deixamos evidente que a nossa visão de EF escolar coaduna com tais elementos trazidos até aqui "COM" a área de Linguagens, buscando em Paulo Freire uma concepção crítico-libertadora (SILVA; MAFRA, 2020).

Provisoriamente, vamos finalizando este debate, buscando em Silva e Mafra (2020) apoio para concordar com suas explanações em que as crianças ainda vivem em uma Educação autoritária, antidialógica e bancária, além de não serem escutadas, imperando a decisão adultocêntrica. É exatamente por isso que se faz necessário trazer para as discussões da $\mathrm{El}$ e da EF, autores/as como Paulo Freire, que na nossa visão significa, concordando com Silva e Mafra (2020), um ato de resistência.

\section{CONSIDERAÇÕES PROVISÓRIAS}


FARIAS, U. de S.; MALDONADO, D. T.; RODRIGUES, G. M.

Este ensaio foi produzido na perspectiva de defender a ideia de que as aulas de $\mathrm{EF}$ "COM" a El podem possibilitar que as crianças desse ciclo de escolarização leiam criticamente o mundo, a partir da problematização de uma ecologia de saberes construídos historicamente sobre as práticas corporais e o corpo. Além disso, para que a cultura deles e delas possa ser efetivamente valorizada, as vivências realizadas nos tempos do componente curricular precisam considerar que as práticas corporais são produzidas a partir de gestos dotados de significados e cultura.

Portanto, a função social da EF se desloca, deixando de ser um componente curricular que visa ao desenvolvimento de habilidades motoras, cognitivas e afetivas das crianças, para se tornar uma área que contribui com uma leitura de mundo mais densa da realidade sobre os saberes que envolvem as danças, lutas, ginásticas, esportes, jogos, brincadeiras e da relação das crianças com o seu corpo. Além disso, ao ler o mundo dessa forma, professores/as e alunos/as precisam problematizar a vida das pessoas que são oprimidas, valorizando as suas produções culturais, saberes e a relação que possuem com as manifestações da cultura corporal.

Essa defesa se torna plausível por conta das contribuições freireanas sobre a leitura de mundo. Fundamentamos os saberes produzidos pelo patrono da educação brasileira sobre essa temática, problematizando a Educação Física como um componente curricular da área de Linguagens e que, como função social, possibilita uma leitura crítica do mundo sobre os conhecimentos que envolvem as práticas corporais e o corpo. Dessa forma, esperamos que este ensaio possa ser um primeiro passo para difundir o pensamento de Paulo Freire na área de EF.

Artigo recebido em: 30/03/2021

Aprovado para publicação em: 29/06/2021

PHYSICAL EDUCATION, LANGUAGE AND CHILDHOOD EDUCATION: AN APPROACH WITH PAULO FREIRE

ABSTRACT: This essay was produced in the perspective of defending the idea that Physical Education classes with Early Childhood Education can enable children to read the world critically, from the problematization of an ecology of knowledge historically built on body practices and the body. In addition, we problematize the relationship between movement and gesture, arguing that human gestures are endowed with meanings, being understood and reframed according to the culture of practitioners of dances, gymnastics, sports, fights, and games. Finally, we show that this epistemological advance in the area was given, among many particularities, by the Freirean theoretical foundation of reading the world, mainly because the curricular component is inserted in the area of Languages in Basic Education.

KEYWORDS: Physical Education. Child Education. Languages. Reading the World. 
RESUMEN: Este ensayo se produjo en la perspectiva de defender la idea de que las clases de Educación Física con la Educación Infantil pueden capacitar a los niños para leer el mundo de manera crítica, a partir de la problematización de una ecología del conocimiento históricamente construida sobre las prácticas corporales y el cuerpo. Además, problematizamos la relación entre movimiento y gesto, argumentando que los gestos humanos están dotados de significados, siendo comprendidos y replanteados según la cultura de los practicantes de bailes, gimnasia, deportes, peleas y juegos. Finalmente, mostramos que este avance epistemológico en el área se debió, entre muchas particularidades, al fundamento teórico de la lectura del mundo de Freire, principalmente porque el componente curricular se inserta en el área del lenguaje en Educación Básica.

PALABRAS CLAVE: Educación Física. Educación Infantil. Lenguaje. Leyendo el Mundo.

\section{REFERÊNCIAS BIBLIOGRÁFICAS}

BOSSLE, F. et al. "SULEAR": uma perspectiva de orientação epistemológica para pesquisa qualitativa crítica na Educação Física Escolar. IN: BOROWSKI, E. B. V.; MEDEIROS, T. N.; BOSSLE, F. Por uma perspectiva crítica na Educaçã Física Escolar: ensaiando possibilidades. Curitiba: CRV, 2020, p. 17-32.

BRASIL. Referencial Curricular Nacional da Educação Infantil. Brasília: Ministério da Educação, 1998.

BRASIL. Diretrizes Curriculares Nacionais para a Educação infantil. Brasília: Ministério da Educação, 2010.

BRASIL. Base Nacional Comum Curricular. Brasília: Ministério da Educação, 2017.

COSTA, M.; ALMEIDA, F. Q. D. A Educação Física e a "Virada Culturalista" do campo: um olhar a partir de Mauro Betti e Valter Bracht. Corpoconsciência, Cuibá-MT, v. 22, n. 1, p. 1-12, Abr. 2018.

EDWARDS, C.; GANDINI, L.; FORMAN, G. As cem linguagens da criança: A abordagem de Reggio Emilia na educação da primeira infância. Porto Alegre: Penso, 2018.

EHRENBERG, M. C. A linguagem da cultura corporal sob o olhar de professores da educação infantil. Pro-posições, São Paulo, v. 25, n. 1, p. 181-198, jan./abr. 2014. 
FARIAS, U. de S.; MALDONADO, D. T.; RODRIGUES, G. M.

FREIRE, P. Pedagogia da Autonomia: saberes necessários à Prática Educativa. São Paulo: Terra e Paz, 2011.

FREIRE, P. Pedagogia do Oprimido. 1. ed. ed. Rio de Janeiro: Paz e Terra, v. 21, 2013.

FREIRE, P. Educação Como Prática da Liberdade. 1. ed. ed. Rio de Janeiro: Paz e Terra, 2015.

FREIRE, P. A importância do Ato de Ler: em três artigos que se completam. $1^{\text {a }}$. ed. São Paulo: Cortez, v. 22, 2017.

GOELZER, J.; HENZ, C. I. Auto(trans)formação permanente com professoras(es) e o esperançar em "um mundo mais bonito", em que todas e todos "possam rir". IN: SILVA, M. R. P.; MAFRA, J. F. Paulo Freire e a Educação das Crianças. São Paulo: BT Acadêmicos, 2020. p. 292-327.

LAZZAROTTI FILHO, A. et al. O termo práticas corporais na literatura científica brasileira e sua repercussão no campo da Educação Física. Movimento, Florianópolis, v. 16, n. 1, p. 11-19, Abr. 2010.

MELLO, A. S. et al. A Educação Infantil na Base Nacional Comum Curricular: pressupostos e interfaces com a Educação Física. Motrivivência. Florianópolis, v. 28, n. 48, p. 130-149, 2016.

NEIRA, M. G. Práticas corporais: brincadeiras, danças, lutas, esportes e ginásticas. São Paulo: Melhoramentos, 2014.

NEIRA, M. G. O que é ler e escrever em Educação Física. In: RODRIGUES, A. M.; FORTUNATO, M. P. Letramento e Alfabetização: prática reflexiva no processo educativo. São Paulo: Humanitas, 2017. p. 1-10.

NEIRA, M. G.; NUNES, M. L. F. Currículo Cultural, Linguagem, Códigos e Representação: uma proposta para a produção de outras formas de fazer, ver e dizer a respeito de si, das práticas corporais e seus praticantes. In: MALDONADO, D. T.; FARIAS, U. D. S.; NOGUEIRA, V. A. Linguagens na Educação Física Escolar: diferentes formas de ler o mundo. Curitiba: CRV, 2021. p. 21-40.

PELOSO, F. C.; PAULA, E. M. T. A. D. Paulo Freire e as crianças: reflexões e olhares sobre a educação da infância. In: SILVA, M. R. P. D.; MAFRA, J. F. Paulo Freire e a educação das crianças. $1^{\text {a }}$. ed. São Paulo: BT Acadêmica, 2020. p. 189-223.

QVORTRUP, J. A infância enquanto categoria estrutural. Educação e Pesquisa, São Paulo, v. 36, n. 2, p. 631-643, Mai./Ago. 2010.

SARMENTO, M. J. A socielogia da infância e a sociedade contemporânea: desafios conceituais e praxeológicos. In: ENS, R. T.; GARANHANI, M. C. Sociologia da Infância e a 
formação de professores. São Paulo: Editora Universitária Champagnat, v. I, 2013. p. 1346.

SARMENTO, M. J.; TOMÁS; C. A infância é um direito? Sociologia: Revista da Faculdade de Letras da Universidade do Porto. Número Temático - Direitos das crianças: abordagens críticas a partir das ciências sociais, p. 15-30, 2020.

SCARAZZATTO, J. Verbo e gesto: formas indissociáveis de compreender e fazer. Revista Brasileira de Educação Física Escolar: Rebescolar, Curitiba, v. 3, p. 145-155, Mar. 2020.

SILVA, A. M.; LAZZAROTTI FILHO, A. L.; ANTUNES, P. D. C. Práticas Corporais. In: GONZÁLEZ, F. J.; FENSTERSEIFER, P. E. Dicionário Crítico de Educação Física. 3a. ed. Ijuí: Unijuí, 2014. p. 522-527.

SILVA, M. R. P. D.; MAFRA, J. F. Apresentação. In: SILVA, M. R. P. D.; MAFRA, J. F. Paulo Freire e Educação das crianças. 1 ${ }^{\text {a }}$ ed. São Paulo: BT Acadêmica, 2020. p. 14-22.

SOUSA SANTOS, B. Epistemologia do Sul. Utopia e práxis latino-americanas, Maracaibo - Venezuela, v. 16, n. 54, p. 17-39, jul./Set. 2011.

\footnotetext{
UIRÁ de SiqueIRA Farias: Doutorando em Educação Física pela Universidade São Judas. Docente nos municípios de São Paulo e Santo André.

Orcid: https://orcid.org/0000-0001-7286-1000

E-mail: uirasiqueira@yahoo.com.br

Daniel Teixeira Maldonado: Doutor em Educação Física pela Universidade São Judas. Pós-Doutor em Educação pela USP. Docente do Instituto Federal de São Paulo.

Orcid: https://orcid.org/0000-0002-0420-6490

E-mail: danieltmaldonado@yahoo.com.br

Graciele MAssoli Rodrigues: Doutora em Educação Física pela UNICAMP. Docente da Universidade São Judas.

Orcid: https://orcid.org/0000-0002-0275-0193

E-mail: masgra@terra.com.br
}

Este periódico utiliza a licença Creative Commons Attribution 3.0, para periódicos de acesso aberto (Open Archives Initiative - OAI) 